\title{
Smooth Particle Hydrodynamics Simulation of Micro-Cup-Extrusion Using a Graphit-ic Coating
}

\author{
Li Shi-Cheng, ${ }^{1}$ Chen Ze-Zhong, ${ }^{2}$ Zheng Jie, ${ }^{1}$ and Wang Dong-Feng ${ }^{1}$ \\ ${ }^{1}$ School of Mechanical Engineering, University of Shanghai for Science and Technology, Shanghai 200093, China \\ ${ }^{2}$ School of Materials Science and Engineering, University of Shanghai for Science and Technology, Shanghai 200093, China \\ Correspondence should be addressed to Chen Ze-Zhong; xtulsc@qq.com
}

Received 4 April 2014; Revised 12 July 2014; Accepted 14 July 2014; Published 21 July 2014

Academic Editor: Pavel Lejcek

Copyright (C) $2014 \mathrm{Li}$ Shi-Cheng et al. This is an open access article distributed under the Creative Commons Attribution License, which permits unrestricted use, distribution, and reproduction in any medium, provided the original work is properly cited.

\begin{abstract}
Microextrusion is becoming increasingly important for the manufacturing of microcomponents. However, this reduction in scale to a microlevel means that the influence of friction and the need for suitable lubrication are greatly increased. This study therefore looks at the use of a low-friction and highly wear resistant Graphit-ic coating on the mold-forming section of a microextrusion mold, this coating being applied by a closed-field unbalanced magnetron sputter ion plating technique. A microcup of CuZn33 brass alloy was then extruded, with a wall thickness of $0.45 \mathrm{~mm}$, outside diameter of $2.9 \mathrm{~mm}$, and an internal diameter of $2 \mathrm{~mm}$. The experimental results in which extrusion uses the mold coating with Graphit-ic film are compared against the experimental results in which extrusion uses the mold uncoating with Graphit-ic film. This showed that the load was decreased a lot and the self-lubricating solid coating facilitates a smooth extrusion process. As the extrusion rate was quite high, smoothed particle hydrodynamics method simulations of the extrusion process were conducted, these being then compared with the experimental results. These result showed that the SPH simulation can be applied to show the deformation of materials and predict the load trend.
\end{abstract}

\section{Backgrounds}

Over the last decade, miniaturization technology has been developed and widely used in the fields of automotive technology, computers, consumer electronics, medicine, aerospace, optics, environmental monitoring, and so forth [1]. At the same time, there has been a greatly increased demand for microcomponents, with the evolution of microelectromechanical systems (MEMS) prompting new microforming technologies. The use of microforming offers many benefits in terms of high efficiency, low material losses, low cost, net shape, and good mechanical properties of the formed components; and, so, it is not surprising that it has been the subject of an increasing number of research studies and practical applications [2-8]. Furthermore, microextrusion has been considered for the extrusion of metallic microcomponents, defined as having dimensions of less than 1 millimeter. Although most existing macroscopic forming technologies are very mature, when the component geometry is scaled down to a level that is close to the grain size an entirely different understanding of the process is required.
At present, most research into microforming has focused on the use of either liquid or solid lubricants to assist the process. Some studies have found that liquid lubricants produce a very pronounced size effect, because differences between the edge and the middle regions result in uneven friction [6-9]. Put simply, as the geometry of components is reduced the friction coefficient is significantly increased, thus resulting in the layer of lubricant becoming uneven and readily aggregated. Furthermore, the large size of most solid lubricant particles causes an unsatisfactory reduction in the surface quality and the shape accuracy of microformed components [10]. The lack of consideration for these factors represents a serious inadequacy of classical friction modeling when applied to microforming. Similarly, existing plastic forming simulations do not consider the size effect of friction problems and thus cannot truly reflect microforming processes. Given this change in the friction mechanism, conventional lubrication methods are often inadequate to address the requirements of microforming; and, therefore, choosing an appropriate new method of lubrication is quite important to ensure high quality microcomponents. Recently, however, 
TABLE 1: Chemical composition of CuZn33.

\begin{tabular}{lccccc}
\hline Material & $\mathrm{Cu}$ & $\mathrm{Fe}$ & $\mathrm{Pb}$ & $\mathrm{P}$ & $\mathrm{Zn}$ \\
\hline$\omega / \%$ & 68.5 & $\leq 0.1$ & $\leq 0.03$ & $\leq 0.01$ & Rem
\end{tabular}

studies have found that the application of a solid lubricant film with a suitable low coefficient of friction can meet the lubrication requirements of quite a varied number of unconventional working conditions [11-13]. Since the use of such films renders the effects of friction in microforming negligible, we can use readily available software to simulate the forming process, the use of self-lubricating films having already attracted the attention of some researchers [14-16].

This study investigates the use of a self-lubricating solid coating of Graphit-ic on the mold-forming section of a microextrusion process used to extrude microcup parts. A closed field unbalanced magnetron sputter ion plating technique was used to produce the coating under a pure argon atmosphere, using graphite as the target material and added chromium to improve the coating's properties. Experimentally obtained results are compared against with the coating and without the coating. Besides, a smoothed particle hydrodynamics (SPH) simulation method was conducted to simulate the metal flow and the Mises stress distributions, as the SPH research is just at the beginning stage; the researchers use it very little in metal deformation, so it is a new attempt; this can provide a train of thoughts for materials process simulation.

\section{Materials and Mold Prepare}

The structure of the microextrusion mold used in this study is shown in Figure 1. The iPhone5 is the reference object; this mold can be divided into an upper and lower assembly, with a cylindrical pin used to guide their alignment. A super-hard tool steel was used for both the punch and cavity, which have respective diameters of 2 and $2.9 \mathrm{~mm}$. Following grinding, polishing, cleaning, and drying of the molds, they were coated with a layer of Graphit-ic using a process described in detail later in this section. The molds were then installed in a universal testing machine, its data acquisition system being used to collect engineering stress-strain data during the extrusion process.

The brass alloy CuZn33 was used in this study, as its iron content of less than $1 \%$ affords it a high strength, good toughness, and excellent plasticity that are ideally suited to extrusion. A detailed summary of the chemical composition of this alloy is provided in Table 1.

To obtain experimental samples of CuZn33 with an average grain size of $30 \mu \mathrm{m}$, an initial heat treatment process was necessary in which the alloy material was first heated in a furnace to $500^{\circ} \mathrm{C}$. At this point, the furnace was switched off and left closed for 30 minutes. The samples were then removed and cooled to room temperature in air. Samples for metallographic observation were first ground and polished to obtain a higher dimensional accuracy and then etched for a minutes in a solution of hydrochloric acid $(10 \mathrm{~mL})$, ferric chloride $(5 \mathrm{~g})$, and distilled water $100 \mathrm{~mL}$. The microstructure
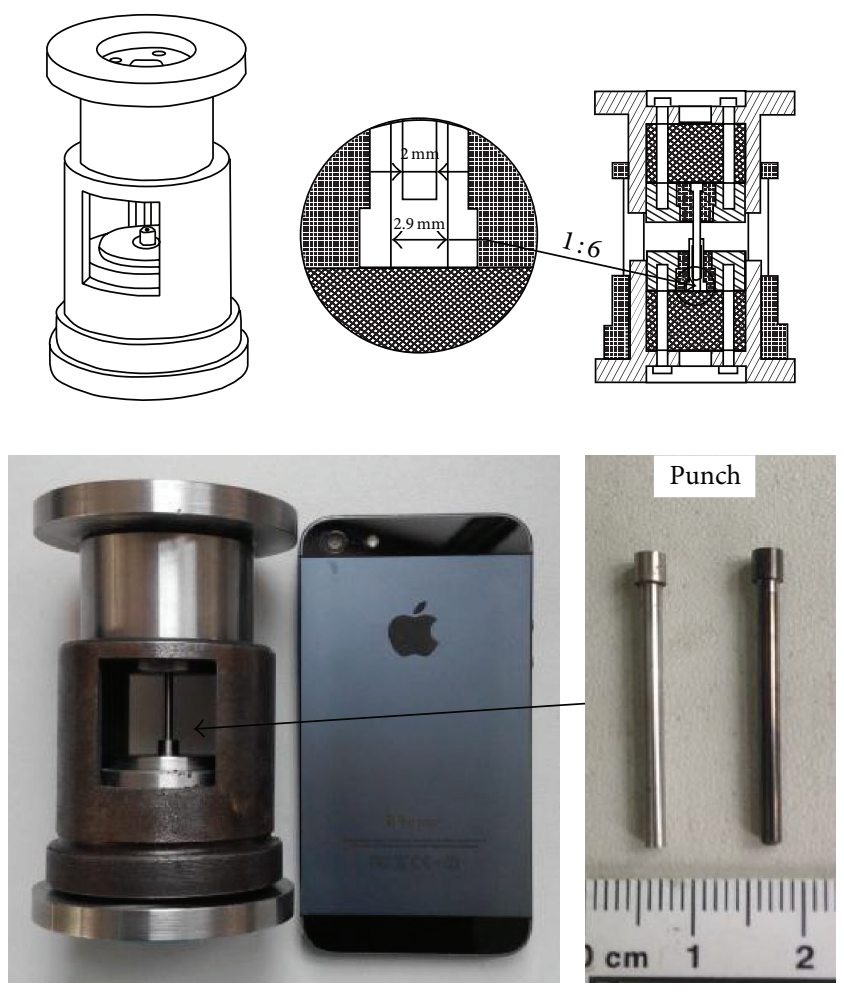

FIGURE 1: The microextrusion mold.

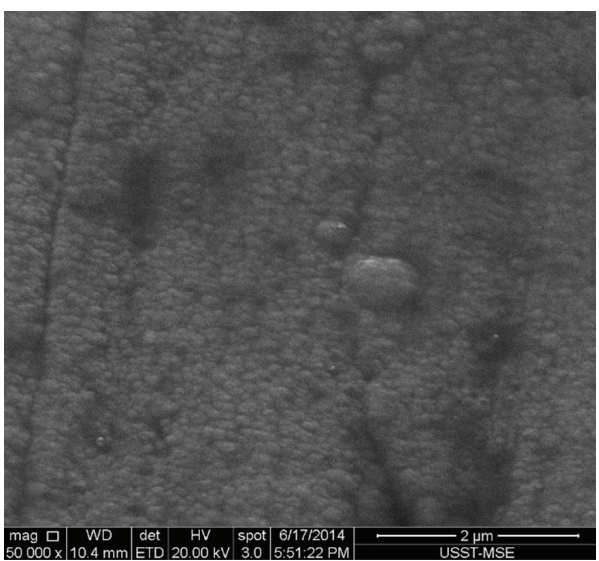

FIGURE 2: Electron micrographs of Graphit-ic coating.

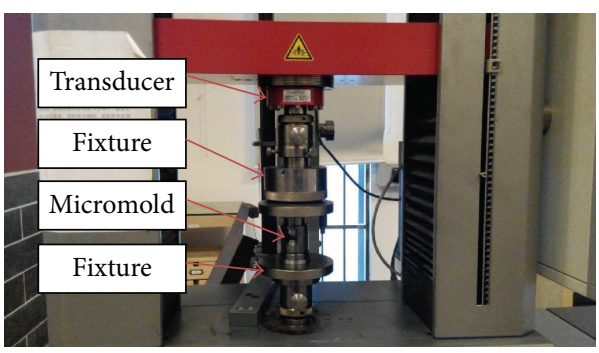

Figure 3: Microextrusion experiments. 


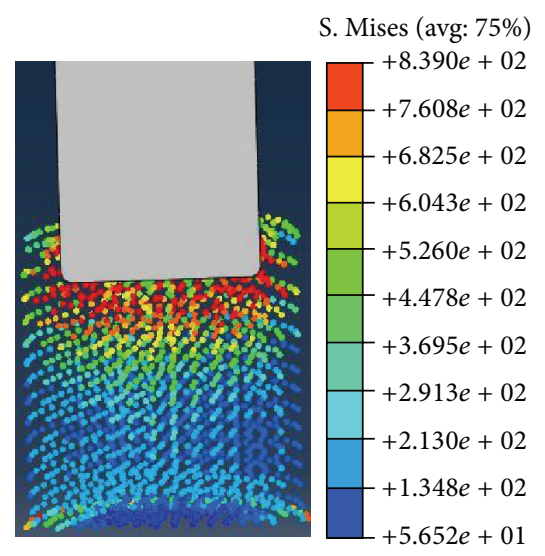

(a)

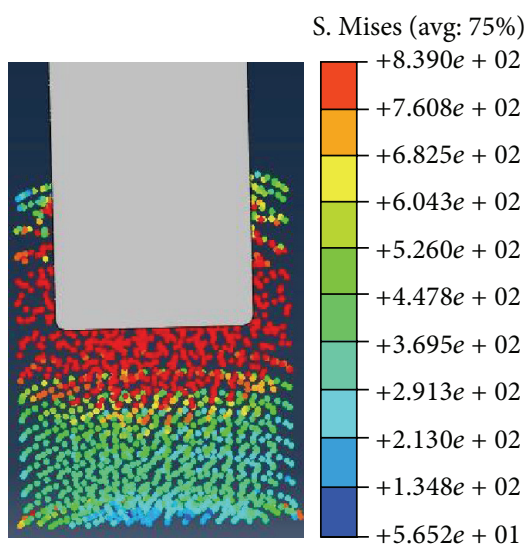

(b)

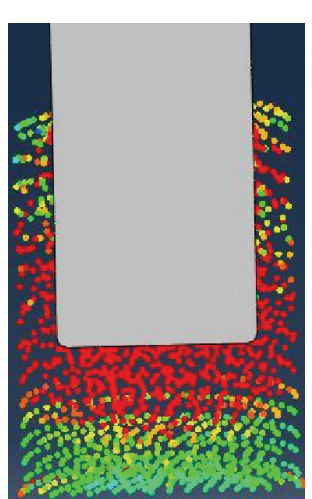

S. Mises (avg: $75 \%$ )

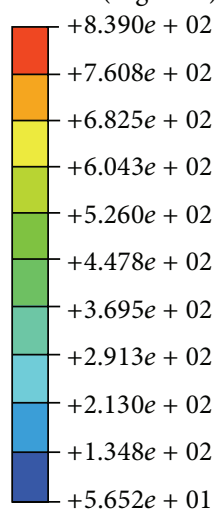

(c)

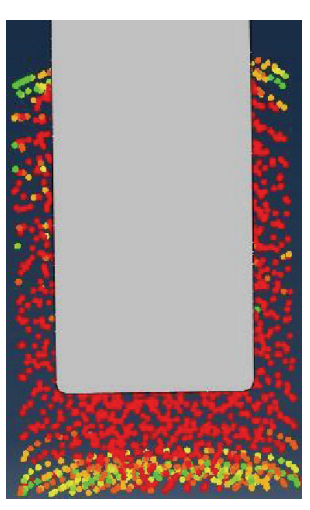

(d)
S. Mises (avg: 75\%)

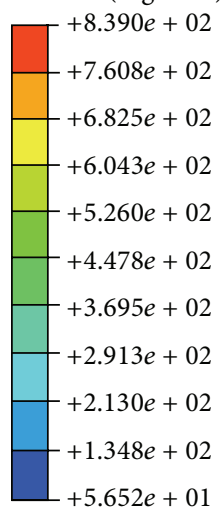

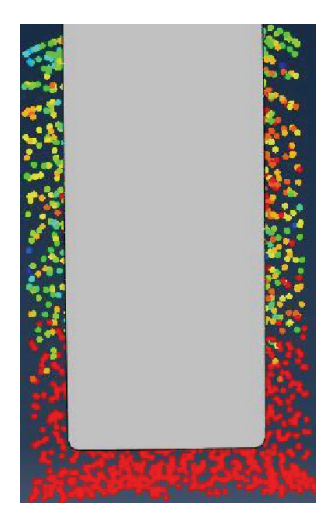

S. Mises (avg: 75\%)

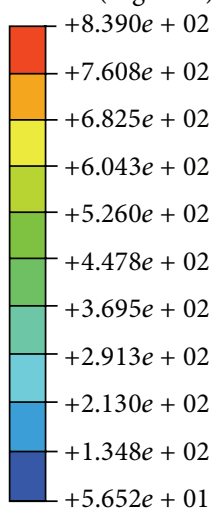

(e)

FIGURE 4: SPH simulation.

TABLE 2: The plastic data of samples.

\begin{tabular}{lcccc}
\hline CuZn33 & Density & Elasticity & $\begin{array}{c}\text { Yield } \\
\text { strength }\end{array}$ & $\begin{array}{c}\text { Poisson's } \\
\text { ratio }\end{array}$ \\
\hline Units & $\mathrm{g} / \mathrm{cm}^{3}$ & $\mathrm{Gpa}$ & $\mathrm{Mpa}$ & - \\
Value & 8.55 & 11.15 & $120-800$ & 0.33 \\
\hline
\end{tabular}

of the brass was then observed using a microscope; the average grain was confirmed at 35 micrometer according to ASTM E112 standards. To facilitate computer simulation, a stress-strain curve of the brass alloy in an annealed state was obtained from a microcompression test, using a ZWICK 50 $\mathrm{KN}$ universal testing machine. This also provided data on the elasticity, Poisson's ratio, plastic deformation, and density of the material, the results of which are shown in Table 2.

Coating of the polished mold sections with a selflubricating Graphit-ic coating was achieved by using a closedfield unbalanced magnetron sputter ion plating technique. For this, the mold surface was first cleaned with argon ions to remove any residual substrate or adsorbed oxide. The process of Graphit-ic coating is in the following.

A certain bias voltage was then applied to $\mathrm{Cr}$ target to deposit a Cr under-layer, and then was gradually switched to a $\mathrm{C}$ target to deposit a $\mathrm{Cr}-\mathrm{C} / \mathrm{Cr}$ buffer layer, thus reducing
TABLE 3: The performance parameters of Graphit-ic coating.

\begin{tabular}{lc}
\hline Classification & Value \\
\hline Hardness & $2000 \sim 2500 \mathrm{HV}$ \\
Thickness & $\leq 2 \mu \mathrm{m}$ \\
Friction & $0.05 \sim 0.09$ \\
Wear rate & $5 \times 10^{-18} \mathrm{~m}^{3} / \mathrm{Nm}$ \\
\hline
\end{tabular}

the $\mathrm{Cr}$ target current at the same time. Finally, the $\mathrm{C}$ target current was fixed close to that of the $\mathrm{Cr}$ target, so as to deposit a graphite coating containing a small amount of Cr. From observations of the film morphology by lowvacuum scanning electron microscopy, as shown in Figure 2, it was found that the Graphit-ic coating was consistently amorphous, uniformly deposited, compact, and smooth. In addition, high-speed friction and wear testing confirmed it to have a low coefficient of friction. The performance parameters were measured, as shown in Table 3.

\section{Experiments and SPH Simulation}

Following heat treatment, the material was manufactured into cylindrical samples with a diameter of $2.9 \mathrm{~mm}$, which 


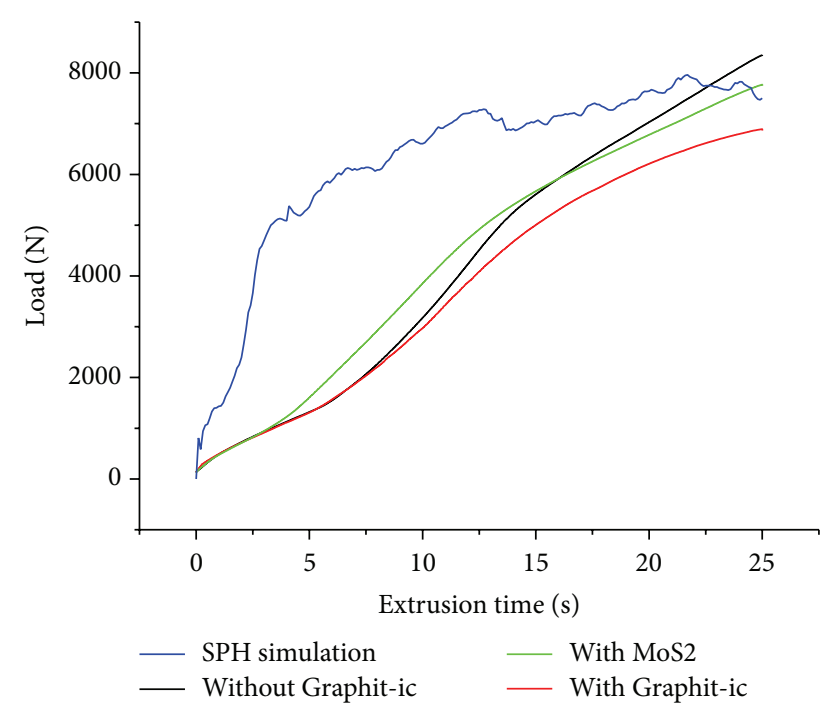

FIGURE 5: Load-time curves of extrusion (SPH simulation, without Graphit-ic coating, lubricate with MoS2, and lubricate with Graphitic coating).

were then polished to obtain a low surface roughness surface. Once loaded into the mold cavity, these polished samples were extruded at a speed of 0.1 millimeter per second. The micro-extrusion-cup experiment is shown in Figure 3. The molds were then installed in a universal testing machine, its data acquisition system being used to collect engineering stress-strain data during the extrusion process. The experiments were split into three groups: the first group extrusion uses the mold coating with Graphit-ic film; the second group extrusion uses the mold without Graphit-ic film; the third group extrusion uses the mold without Graphit-ic film but lubricate with MoS2. The engineering stress-time curve for extrusion was recorded, being taken as the true value to develop a true stress-time curve.

The smoothed particle hydrodynamics method was first developed by Lucy in the year 1977, originally for astrophysics and other related subject areas. From then until the 1990s, the development of theoretical study and practical application led to its use being gradually extended to high-speed collisions, metal forming, molecular dynamics, casting, industrial processing, and friction of solids. The SPH method represents a pure Lagrange particle algorithm, and, having a fixed mass of movable points (particle or node) to discrete, it was based on interpolation theory. Macrovariables such as pressure, temperature, and density are set by means of a random dot value represented by the integral to calculate, while the kernel function extends a single particle surrounded by space to the group of particles near it. In this way, the computational efficiency and accuracy is influenced by a parameter called "smooth dimension," which is the interaction distance between particles; or more specifically, the effective distance of the kernel function that determines for a specific particle the number of approaching particles. Since the billets in this study had a homogeneous density and regular shape, we used a fixed smooth length in order to quickly find particles in the support domain and thereby save on computing time.

\section{Discussion}

Figure 4 shows the simulation process of microextrusion; these figures show the reveal von Mises stress distributions at $5,10,15,20$, and 25 second, as represented, respectively, by Figures 4(a)-4(e). As can be seen from these figures that the Mises stress near the punch is bigger than the area far away from the punch; the particles were concentrated near the punch, showing the larger deformation and density; this law can be confirmed by Figure 6 .

Figure 5 shows the process of microextrusion, the first curve representing the SPH simulation results, the second curve represents the experimental results in which extrusion uses the mold uncoating with Graphit-ic film. The third curve represents the experimental results in which extrusion uses the mold lubricating with MoS2, whereas the forth curve represents the experiment results in which extrusion uses the mold coating with Graphit-ic film. Respectively, as can be seen from the simulations and experiments, the pressure slowly increases at the beginning of the extrusion process and then rapidly increases after $5 \mathrm{~s}$, reaching a relative stable state after $15 \mathrm{~s}$. Beyond this point, the pressure begins to increase slowly again until reaching the $25 \mathrm{~s}$ that marks the end of extrusion. As can be seen from the experiments, extruding with Graphit-ic coating mold, due to its lower coefficient, the materials flow easier, so the load is lower than extruding without Graphit-ic coatings or lubricate with MoS2, demonstrating that this method is feasible. Moreover, these results show that the experimental and simulated loadtime curves exhibit the similar trend with regards to pressure, the maximum pressure at the end of extrusion is also very similar, but we must acknowledge that the SPH simulation and the experiment still have some differences; it is the areas to improve in the future. To some extent, the SPH simulation can be applied to show the deformation of materials and predict the load trend.

The micro-extrusion-cup is shown in the left side of Figure 6, the figure also showing the microextrusion mold. From the high-dimensional precision and smooth surface evident in this microcup, it can be concluded that solid selflubricating mold coatings are effective for the extrusion of quality microparts. In particular, the microstructures of the upper, middle, and bottom sections of the cup show evidence of grain rotation, elongation, and deformation, which thus enabled a more compact structure.

\section{Conclusions}

(1) The Graphit-ic solid coating produced was found to be amorphous, uniform, compact, and to possess a low surface roughness. This created a low-friction coefficient, making it an excellent self-lubricating solid coating for use in the extrusion; the load decreased when lubricating with Graphit-ic coating; it can be chosen as a proper lubricant for microextrusion forming.

(2) Use of the SPH method to simulate microforming processes can reflect their extrusion behavior and predict the load trend. But this method needs to 

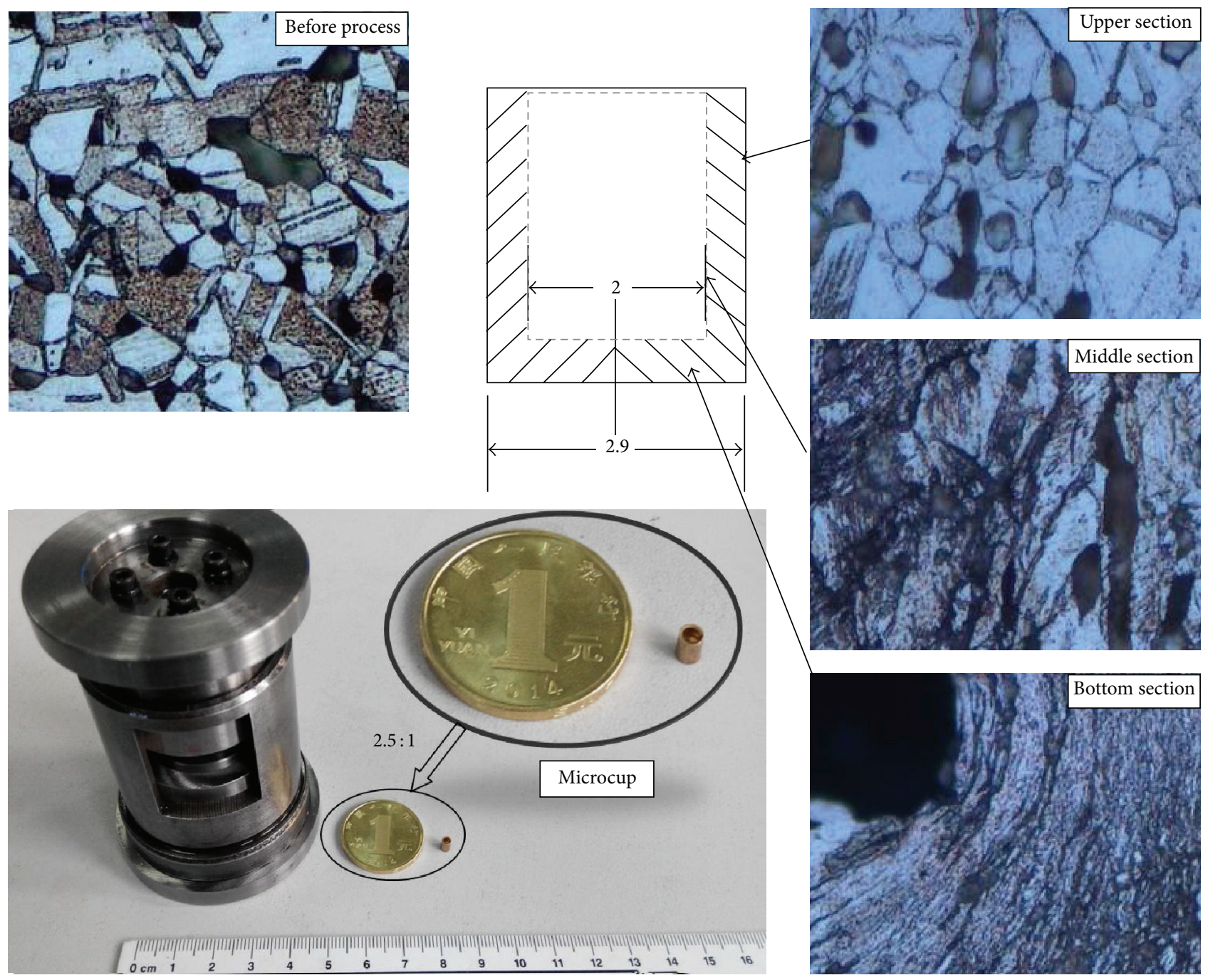

Figure 6: The micromold, the microcup, and the grain changes.

improve its accuracy in the future. Furthermore, it can be applied to visually show the deformation of the material; this study considers that SPH is totally viable method for extrusion simulation.

\section{Conflict of Interests}

The authors declare that there is no conflict of interests regarding the publication of this paper.

\section{Acknowledgments}

This research was supported by The Innovation Fund Project for Graduate Student of Shanghai (Grant no. JWCXSL1302). The authors would like to thank XIE Jun-Jie from Shenzhen Kingmag Precision Technology Co., Ltd., for excellent technical support.

\section{References}

[1] F. Vollertsen, Z. Hu, H. S. Niehoff, and C. Theiler, "State of the art in micro forming and investigations into micro deep drawing," Journal of Materials Processing Technology, vol. 151, no. 1-3, pp. 70-79, 2004.

[2] C. Bunget and G. Ngaile, "Influence of ultrasonic vibration on micro-extrusion," Ultrasonics, vol. 51, no. 5, pp. 606-616, 2011.

[3] W. L. Chan, M. W. Fu, and J. Lu, "Experimental and simulation study of deformation behavior in micro-compound extrusion process," Materials and Design, vol. 32, no. 2, pp. 525-534, 2011.

[4] M. Geiger, M. Kleiner, R. Eckstein, N. Tiesler, and U. Engel, "Microforming," CIRP Annals-Manufacturing Technology, vol. 50, no. 2, pp. 445-462, 2001.

[5] K. Hirota, "Fabrication of micro-billet by sheet extrusion," Journal of Materials Processing Technology, vol. 191, no. 1-3, pp. 283-287, 2007.

[6] W. L. Chan and M. W. Fu, "Studies of the interactive effect of specimen and grain sizes on the plastic deformation behavior in microforming," International Journal of Advanced Manufacturing Technology, vol. 62, no. 9-12, pp. 989-1000, 2012. 
[7] W. L. Chan, M. W. Fu, and B. Yang, "Study of size effect in microextrusion process of pure copper," Materials and Design, vol. 32, no. 7, pp. 3772-3782, 2011.

[8] S. A. Parasiz, B. Kinsey, N. Krishnan, J. Cao, and M. Li, "Investigation of deformation size effects during microextrusion," Journal of Manufacturing Science and Engineering, Transactions of the ASME, vol. 129, no. 4, pp. 690-697, 2007.

[9] J. F. Michel and P. Picart, "Size effects on the constitutive behaviour for brass in sheet metal forming," Journal of Materials Processing Technology, vol. 141, no. 3, pp. 439-446, 2003.

[10] F. Gong and B. Guo, "Effects of solid lubrication film on SKD11 in micro sheet forming," Surface and Coatings Technology, vol. 232, pp. 814-820, 2013.

[11] N. Krishnan, J. Cao, and K. Dohda, "Study of the size effects on friction conditions in microextrusion-part I: microextrusion experiments and analysis," Journal of Manufacturing Science and Engineering, Transactions of the ASME, vol. 129, no. 4, pp. 669676, 2007.

[12] Z. Hu, A. Schubnov, and F. Vollertsen, "Tribological behaviour of DLC-films and their application in micro deep drawing," Journal of Materials Processing Technology, vol. 212, no. 3, pp. 647-652, 2012.

[13] K. Fujimoto, M. Yang, M. Hotta et al., "Fabrication of dies in micro-scale for micro-sheet metal forming," Journal of Materials Processing Technology, vol. 177, no. 1-3, pp. 639-663, 2006.

[14] J. Stallard and D. G. Teer, "A study of the tribological behaviour of CrN, Graphit-iC and Dymon-iC coatings under oil lubrication," Surface and Coatings Technology, vol. 188-189, no. 1-3, pp. 525-529, 2004.

[15] X. Niu, X. Wang, S. Ma, K. Xu, and W. Liu, "Structure and properties of the Graphit-ic and Dymon-ic coatings," Rare Metal Materials and Engineering, vol. 34, no. 8, pp. 1291-1294, 2005 (Chinese).

[16] S. K. Field, M. Jarratt, and D. G. Teer, "Tribological properties of graphite-like and diamond-like carbon coatings," Tribology International, vol. 37, no. 11-12, pp. 949-956, 2004. 

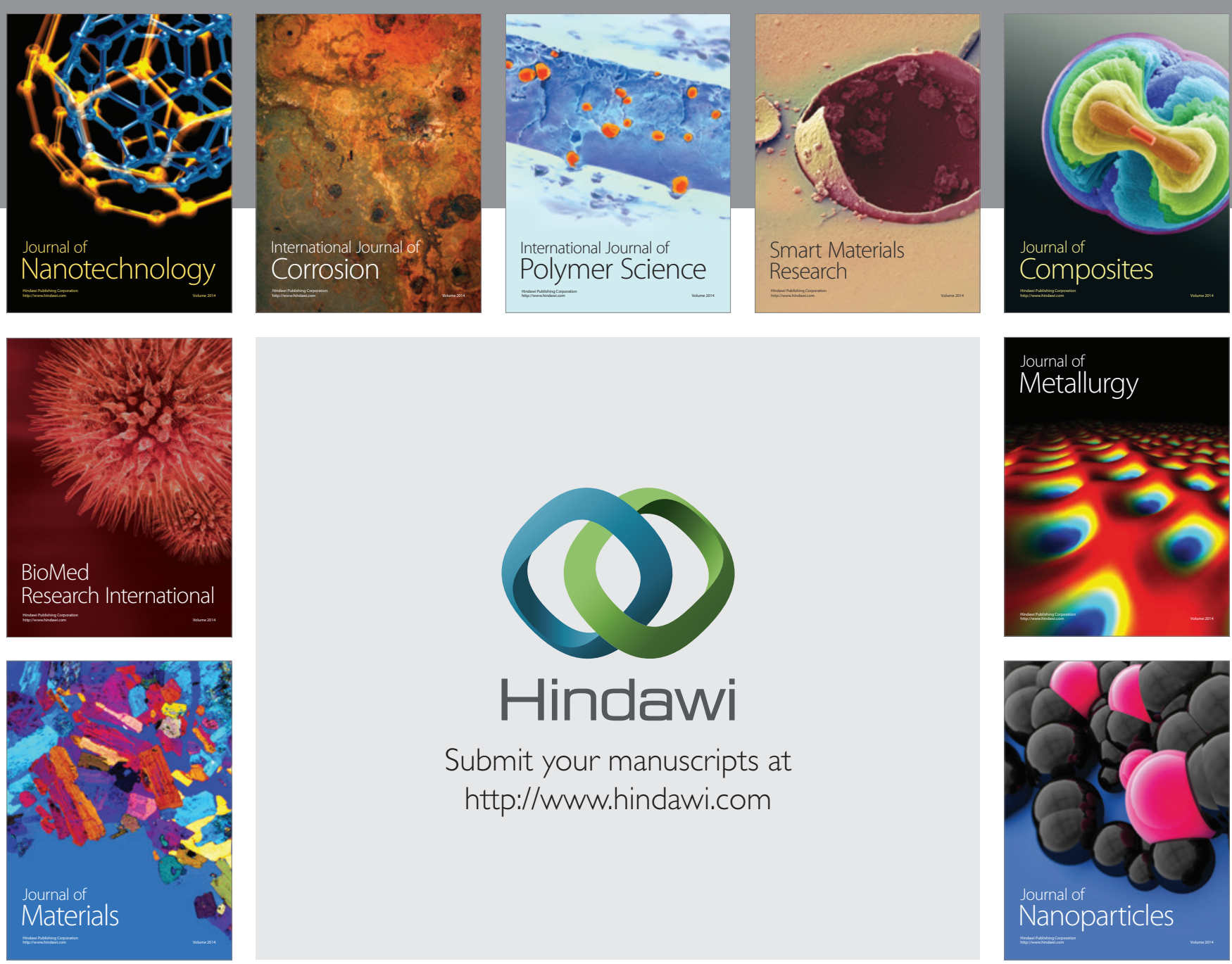

Submit your manuscripts at http://www.hindawi.com
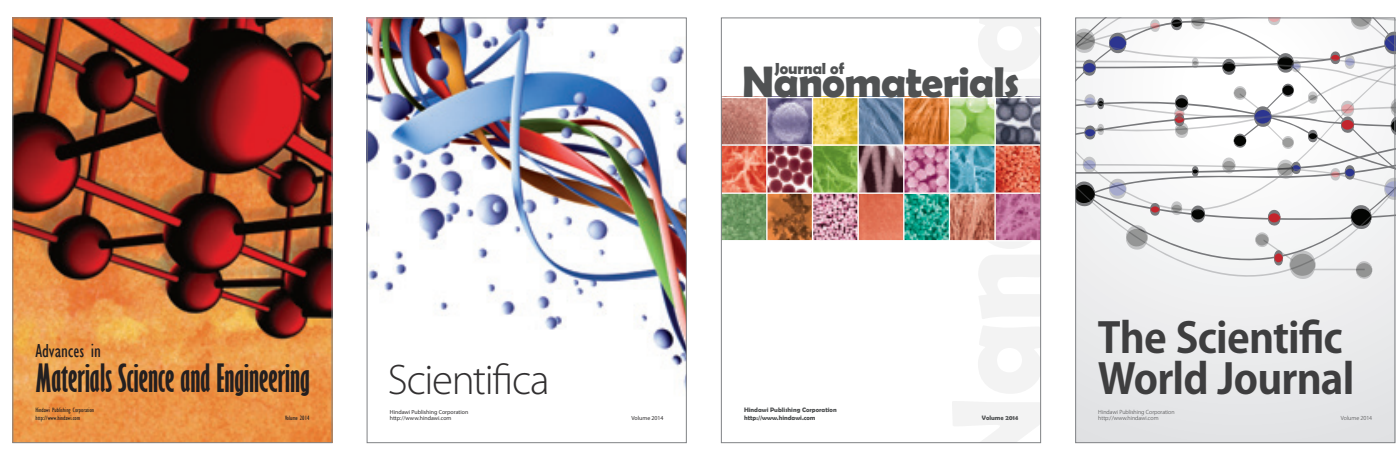

\section{The Scientific World Journal}
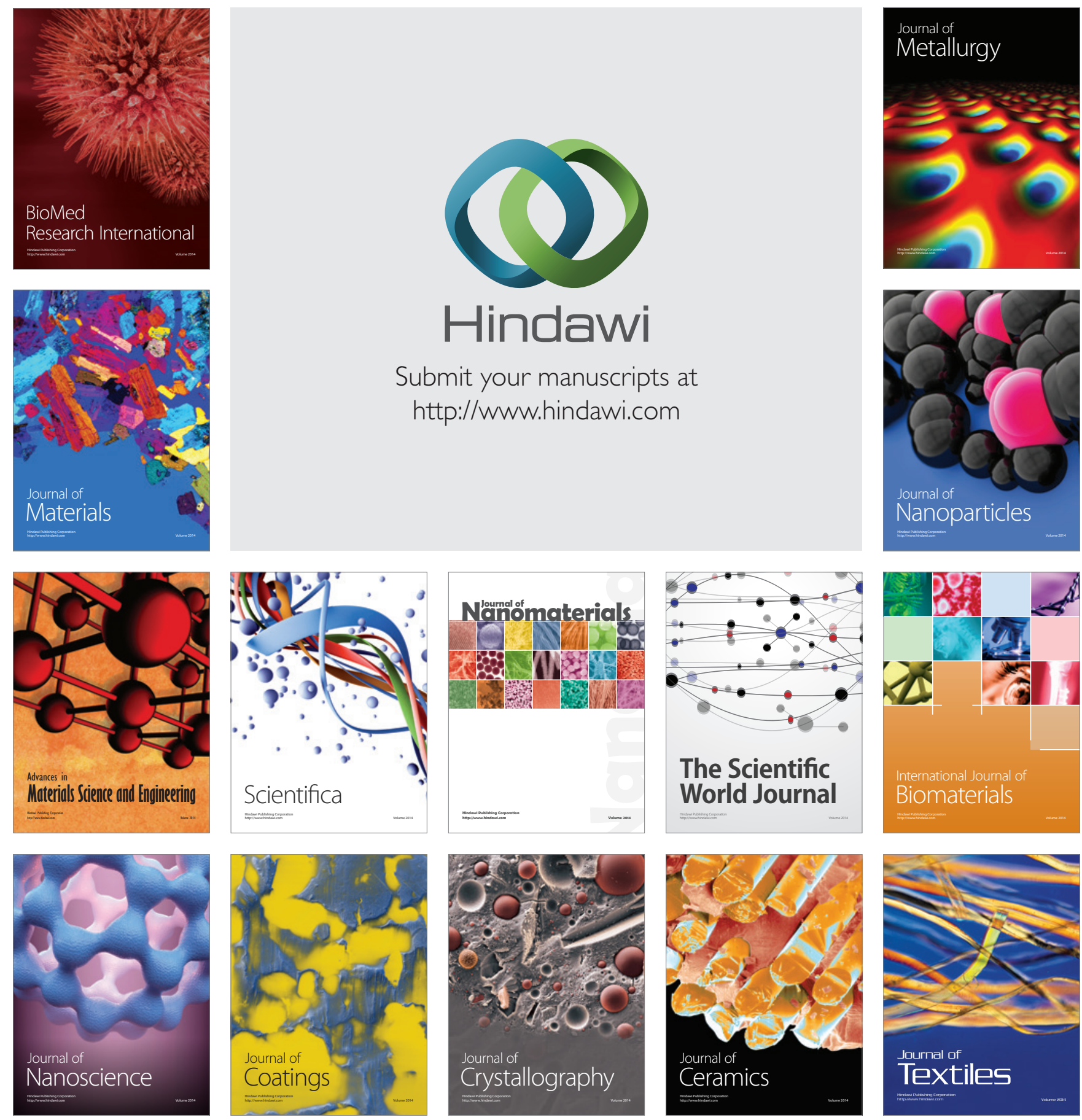